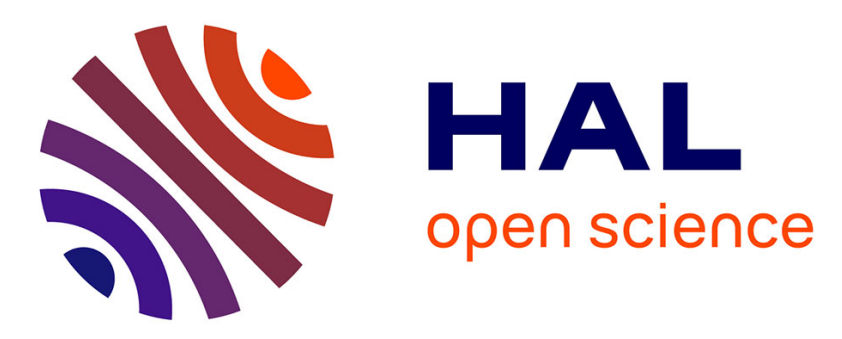

\title{
Impact of the In Situ Creation of an Epoxy Based Thermosetting Minor Phase on the Physical Properties of a PP Based Blend
}

Luísa Barroso Gago, Mathilde Auclerc, Karim Delage, Nicolas Garois, Philippe Cassagnau, Véronique Bounor-Legaré

\section{To cite this version:}

Luísa Barroso Gago, Mathilde Auclerc, Karim Delage, Nicolas Garois, Philippe Cassagnau, et al.. Impact of the In Situ Creation of an Epoxy Based Thermosetting Minor Phase on the Physical Properties of a PP Based Blend. Industrial and engineering chemistry research, 2021, 60 (15), pp.54215431. 10.1021/acs.iecr.0c05963 . hal-03413432

\section{HAL Id: hal-03413432 \\ https://hal.science/hal-03413432}

Submitted on 3 Nov 2021

HAL is a multi-disciplinary open access archive for the deposit and dissemination of scientific research documents, whether they are published or not. The documents may come from teaching and research institutions in France or abroad, or from public or private research centers.
L'archive ouverte pluridisciplinaire HAL, est destinée au dépôt et à la diffusion de documents scientifiques de niveau recherche, publiés ou non, émanant des établissements d'enseignement et de recherche français ou étrangers, des laboratoires publics ou privés. 
This document is confidential and is proprietary to the American Chemical Society and its authors. Do not copy or disclose without written permission. If you have received this item in error, notify the sender and delete all copies.

\section{Impact of the in situ creation of an epoxy based thermosetting minor phase on the physical properties of a PP based blend}

\begin{tabular}{|r|l|}
\hline Journal: & Industrial \& Engineering Chemistry Research \\
\hline Manuscript ID & ie-2020-05963v.R2 \\
\hline Manuscript Type: & Article \\
\hline Date Submitted by the & n/a \\
\hline Complete List of Authors: & $\begin{array}{l}\text { Barroso Gago, Luisa; Universite Claude Bernard Lyon 1, UMR 5223 } \\
\text { Ingénierie des Matériaux } \\
\text { Auclerc, Mathilde; Universite Claude Bernard Lyon 1, UMR 5223 } \\
\text { Ingénierie des Matériaux } \\
\text { DELAGE, Karim; Universite Claude Bernard Lyon 1, UMR 5223 Ingénierie } \\
\text { des Matériaux } \\
\text { Garois, Nicolas; Hutchinson SA } \\
\text { Cassagnau, Philippe; Universite Claude Bernard Lyon 1, UMR 5223 } \\
\text { Ingénierie des Matériaux } \\
\text { Bounor-Legaré, Véronique; CNRS, Ingénierie Des Matériaux Polymères }\end{array}$ \\
\hline
\end{tabular}

\section{SCHOLARONE Manuscripts}




\title{
Impact of the in situ creation of an epoxy based thermosetting minor phase on the physical properties of a PP based blend
}

\author{
Luísa Barroso Gago ${ }^{a}$, Mathilde Auclerc $^{a}$, Karim Delage ${ }^{a}$, Nicolas Garois $^{b}$, Philippe \\ Cassagnau ${ }^{a}$ Véronique Bounor-Legaréa*
}

a Univ Lyon, Université Lyon1, CNRS UMR 5223, Ingénierie des Matériaux Polymères, F-69622, LYON, France ; *bounor@univ-lyon1.fr

b Hutchinson, Centre de Recherche, Rue Gustave Nourry - B.P. 31, 45120, Chalette-surLoing, France

\begin{abstract}
As an alternative to inorganic fillers based composites which present high density, an epoxy based thermosetting (TS) phase was in situ created in a polypropylene (PP) matrix and compatibilized by a polypropylene grafted maleic anhydride (PP-g-MA). The aim of this study is to scrutinize the chemistry and establish a relation between the morphology, the mechanical properties and the crystalline structure of this thermosetting/thermoplastic system. Depending of the components concentration, dispersed phase of around $0.5 \mu \mathrm{m}$ diameter (even with smaller nodules) are created with the presence of PP-g-MA. Moreover, an increase up to $24 \%$ of the Young's modulus of the system is observed and the resilience is maintained. The evolution of the PP crystallinity by Wide Angle X-rays scattering (WAXS) evidenced that TS is a $\beta$ nucleating agent at the origin of an excellent toughness and impact strength.
\end{abstract}




\section{INTRODUCTION}

Polypropylene (PP) is a widely known and used polymer and its production represents $20 \%$ of the total production ${ }^{1}$ of plastic in Europe in 2016 . Its use covers almost all types of industries, from food packaging to automotive parts passing by bank notes. PP is an attractive polymer due to its low cost, high macromolecular diversity, low density and it is inert to other chemicals. Even though, it has a fair good mechanical strength at room temperature and becomes brittle at low temperature since its glass transition is around $0{ }^{\circ} \mathrm{C}$. To benefit of the qualities of PP and to replace expensive polymers, physical and chemical modifications are required in order to reinforce PP. Among those modifications, three were widely studied.

Polymer blends ${ }^{2-4}$ are very complex and have been studied for almost 30 years. Indeed, in some cases it is possible to merge the best properties of each polymer, by increasing the performance of the final material. In addition, they generally have a lower impact than developing completely new materials. However, almost all polymers with different chemical structures are immiscible, thus causing phase separation, which is problematic for the final properties of the material.

Several studies also discuss the effects of the incorporation of inorganic fillers ${ }^{5-7}$ such as glass fiber, talc, silica, etc. A very positive impact on mechanical and viscosity is observed without compromising the feasibility and the cost of these fillers is usually very low. Although, incorporation of inorganic fillers is very attractive, its limitation is the impact on the density of the material depending of the inorganic filler concentration usually quite high ${ }^{8,9}$. 
In order to overcome this limitation, the addition of organic fillers into thermoplastics has aroused increasing interest and experimentation during the last years. This technique has been widely used to improve certain intrinsic properties of conventional matrices (PS, PE, EVA) such as barrier properties ${ }^{10}$, tensile strength properties ${ }^{11}$ or even viscosity $^{12}$. This type of modification was chosen in the present work, more precisely the in situ creation of epoxy based thermosetting (TS).

However, as PP is chemically inert, the in situ creation of a new polymer can have the opposite effect and decrease some properties such as resilience if any chemical bond has been created between both phases. Therefore, using a compatibilizer seems essential. The introduction of a di-block copolymer ${ }^{13}$ in the blend is commonly used to compatibilize two immiscible polymers. Indeed, this copolymer composed of two blocks, each miscible or of the same nature of the components of the blend, will assure the link between the immiscible polymers. Another possibility is the in situ formation of a copolymer ${ }^{14,15}$ by chemical reaction at the interface between the phases during the preparation of the blend. The type of compatibilizer used in this work is a polypropylene grafted with maleic anhydride (PP-g-MA), a modified homopolymer' ${ }^{16}$, often used as coupling additive for filled polypropylene and polymer blends ${ }^{17}$, as pigment dispersant, etc. This compatibilizer introduced in not classical concentration will be an important point in our study in order to understand its influence and its role in the creation of epoxy based thermosetting (TS) in the PP matrix.

Besides, in semi-crystalline polymers, such as polypropylene, the crystalline structure is very sensitive and its modification can have an important impact on macroscopic properties. The lamellar orientation ${ }^{18}$, the lamellar thickness ${ }^{19}$ and the degree of crystallinity can have a direct effect on the Young's modulus and resilience. 
In the case of polypropylene, another parameter has to be considered, since different types ( $\alpha$-monoclinic, $\beta$-hexagonal, $\gamma$-triclinic and smectic) of crystalline forms can be encountered. Each structure can lead to PP with quite different mechanical properties. Actually, $\beta$-polypropylene ${ }^{20}$ is known to have excellent toughness and impact strength, in comparison with the $\alpha$-PP, the most common crystalline form. Cascone and Fulchiron $^{21}$, showed that a $\beta$-polypropylene can be obtained by a squeeze flow from an isotactic polypropylene (iPP) initially containing only an $\alpha$-phase. This phenomenon is generally developed in specific conditions such as the presence of nucleating agents. The influence of these agents has been widely studied in the literature. Papageorgiou et al. described a non-exhaustive list of different $\beta$-nucleating agents which mostly are inorganic fillers, for example calcium derivates are often described as really performant $^{22,23}$. Nevertheless, some organic fillers can play the role of $\beta$-phase promoter as studied by Zhang ${ }^{24} \mathrm{et}$ al. with the use of an acylamino-nucleating based-agent. Indeed, the isotactic PP studied presented at first no hexagonal form but with the addition of $0.3 \mathrm{wt} \%$ of nucleating agent, $87 \%$ of the crystallization of iPP was found to be with $\beta$ form. The appearance of this hexagonal modification increased the elongation at break (from $150 \%$ without nucleating agent to $500 \%$ with $0.2 \mathrm{wt} \%$ of filler) and doubled the impact strength.

The main objective of this work is to investigate chemical, structural and morphological parameters initiating the mechanical properties improvement with the in situ creation of an epoxy based thermosetting phase TS in a PP matrix. The first part of this paper will discuss the chemical interaction between the PP matrix, the compatibilizer and the TS phase in situ created as well as its morphology. The second part will focus on the impact of the creation of the TS phase in the amorphous phase mobility and crystallinity of the 
PP. Eventually, the third part will try to establish a relation between the morphology, the crystalline structure modifications and the mechanical properties improvements.

\section{MATERIALS AND FORMULATIONS}

\subsection{Materials and reagents}

Polypropylene (PP) PPH 3060 was supplied by Total. The melt flow index is $1.8 \mathrm{~g} .10 \mathrm{~min}^{-1}$ (in the following conditions: $2.16 \mathrm{~kg} / 230^{\circ} \mathrm{C}$.) and the zero shear viscosity $\eta_{0}=700$ Pa.s at $\mathrm{T}=200{ }^{\circ} \mathrm{C}$. The density of this polymer is $0.90 \mathrm{~g} . \mathrm{cm}^{-3}$ at room temperature and the melting point at $\mathrm{T}_{\mathrm{m}}=165^{\circ} \mathrm{C}$ was measured by differential scanning calorimetry (DSC) analysis.

Maleic anhydride functionalized polypropylene, PP-g-MA, produced by Exxelor (PO 1020) was used as a compatibilizer since the PP is chemically inert. The maleic anhydride mass grafting rate was determined by acid-base titration and it was found at $0.7 \mathrm{wt} \%$ after purification ( $1.2 \mathrm{wt} \%$ before purification). Its number-average molar mass was evaluated at $36200 \mathrm{~g}^{\mathrm{mol}}{ }^{-1}$ by size exclusion chromatography (SEC) in trichlorobenzene $(\mathrm{TCB})$ at $110^{\circ} \mathrm{C}$.

The DER 671, a low molar mass epoxy based-resin developed by Dow Chemicals, was used for both formulations in this study (DER 671/NBDA and DER 671/DEH 84). In order to create an epoxy based thermosetting phase, a cycloaliphatic diamine was chosen for one of the formulations, the norbornane diamine (NBDA) was provided by MitSui Chemicals in liquid state. For the second formulation, DEH 84, an epoxy curing agent which is a phenolic harder, as well from Dow Chemicals, was used to create the second epoxy-based thermosetting network. All the formulations were prepared under stoichiometric conditions (an epoxy function for one amine proton or hydroxy proton) 
with regard to the creation of thermosetting (Table 1). All reagents and matrix are commercial products that were used without any further purification, their structure and the main characteristics are showed in Table 2. 
Table 1 : Epoxy based thermosetting systems studied

\begin{tabular}{|c|c|c|}
\hline Epoxy & Amine/phenolic hardener & $\begin{array}{c}\text { Mass proportions at function stoichiometry } \\
\text { (Epoxy : Amine/Hydroxyl) }\end{array}$ \\
\hline DER 671 & DEH 84 & $1: 2$ \\
\hline DER 671 & NBDA & $13: 1$ \\
\hline
\end{tabular}

Table 2 : Main characteristics of the materials used

\begin{tabular}{|c|c|c|c|c|}
\hline Products & Chemical Structure & Supplier & $\mathrm{T}_{\mathrm{m}} / \mathrm{T}_{\mathrm{g}}\left({ }^{\circ} \mathrm{C}\right)$ & $M\left(\mathrm{~g} \cdot \mathrm{mol}^{-1}\right)$ and MFI \\
\hline $\begin{array}{l}\text { Polypropylene } \\
\text { PPH3060 (PP) }\end{array}$ & & Total & $\mathrm{T}_{\mathrm{m}}=165^{\circ} \mathrm{C}$ & $\begin{array}{c}M_{w}=384000 \text { g. } \mathrm{mol}^{-1 *} \\
\mathrm{MFI}=1.8 \mathrm{~g} .10 \mathrm{~min}^{-1} \\
\left(2.16 \mathrm{~kg} / 230^{\circ} \mathrm{C}\right)\end{array}$ \\
\hline $\begin{array}{l}\text { Polypropylene } \\
\text { grafted maleic } \\
\text { anhydride, } \\
\text { PP-g-MA } \\
\text { PO1020 }\end{array}$ & & Exxon Mobil & $\mathrm{T}_{\mathrm{m}}=167^{\circ} \mathrm{C}$ & $\begin{array}{l}\text { Grafting rate } \mathrm{MA}=0.7 \% * \\
\begin{array}{c}M_{n}=36000 \mathrm{~g} \cdot \mathrm{mol}^{-1} * \\
\mathrm{MFI}=125 \mathrm{~g} .10 \mathrm{~min}^{-1} \\
\left(1.2 \mathrm{~kg} / 190^{\circ} \mathrm{C}\right)\end{array}\end{array}$ \\
\hline $\begin{array}{c}\text { Epoxide resin } \\
\text { DER671 }\end{array}$ & with $\mathrm{n}=1,6$ & $\begin{array}{c}\text { Dow } \\
\text { Chemicals }\end{array}$ & $\mathrm{T}_{\mathrm{g}}=57^{\circ} \mathrm{C}$ & $M_{n}=795 \mathrm{~g} \cdot \mathrm{mol}^{-1}$ \\
\hline
\end{tabular}




\begin{tabular}{|c|c|c|c|c|}
\hline Products & Chemical Structure & Supplier & $\mathrm{T}_{\mathrm{m}} / \mathrm{T}_{\mathrm{g}}\left({ }^{\circ} \mathrm{C}\right)$ & $M\left(\mathrm{~g} \cdot \mathrm{mol}^{-1}\right)$ and MFI \\
\hline $\begin{array}{l}\text { Epoxide resin } \\
\text { DEH84 } \\
\text { (70wt } \% \text { of DER671 } \\
\text { contained in this } \\
\text { hardener) }\end{array}$ & $70 \mathrm{wt} \%$ & $\begin{array}{c}\text { Dow } \\
\text { Chemicals }\end{array}$ & $\mathrm{T}_{\mathrm{g}}=43^{\circ} \mathrm{C}$ & $M_{n}=630 \mathrm{~g} \cdot \mathrm{mol}^{-1 *}$ \\
\hline $\begin{array}{c}\text { Norbornane diamine } \\
\text { (NBDA) }\end{array}$ & $\mathrm{NH}_{2}$ & $\begin{array}{c}\text { TCI } \\
\text { Chemicals }\end{array}$ & $\begin{array}{l}\text { Liquid at } \\
\text { room } \\
\text { temperature }\end{array}$ & $M=154 \mathrm{~g} \cdot \mathrm{mol}^{-1}$ \\
\hline
\end{tabular}

* Experimental values characterized in our laboratory by ${ }^{1} \mathrm{H}$ NMR, by steric exclusion chromatography (SEC) and by acid-base titration 


\subsection{Samples preparation}

Samples were synthetized by melt blending in a co-rotating twin-screw extruder (Leistritz LSM Model, $\mathrm{L} / \mathrm{D}=60, \mathrm{D}=18 \mathrm{~mm}$ ) at $200{ }^{\circ} \mathrm{C}$. In order to ensure sufficient shearing and mixing, the screws profile contains two reverse conveying elements. The screw profile is shown in Figure 1.

PP, PP-g-MA, DER 671 and DEH 84

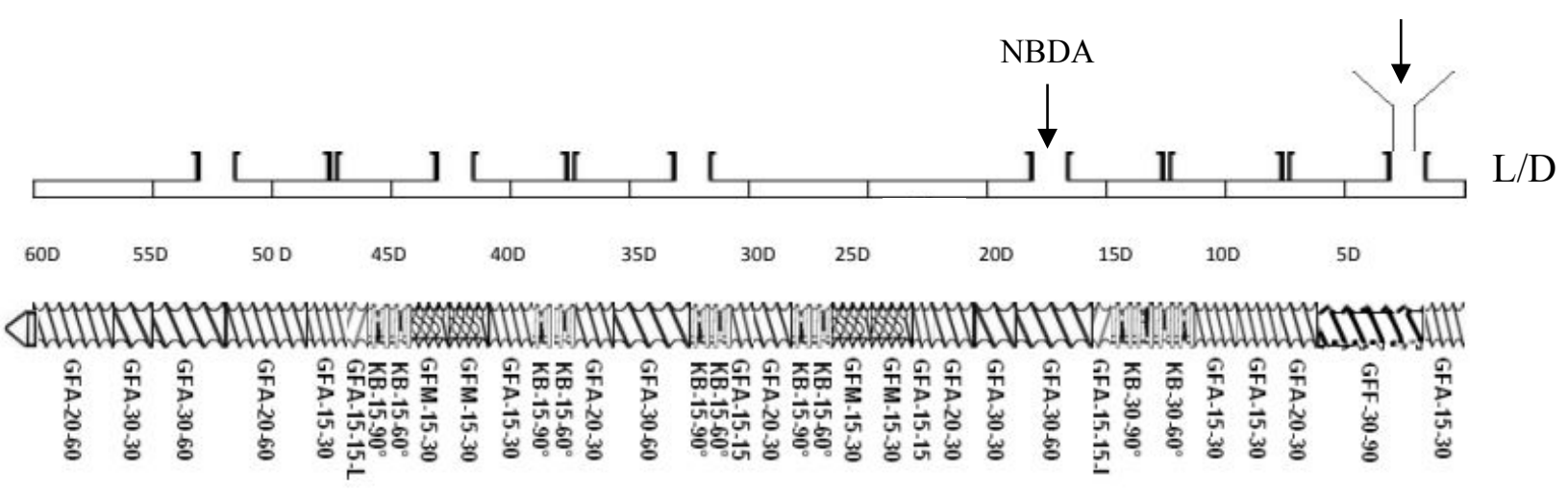

Figure 1 : Twin-screw profile with two reserve convoying elements.

Screw speed was fixed at $800 \mathrm{rpm}$ and the matrix was added by the hopper at a flow rate of 3 kg.h ${ }^{-1}$ with the compatibilizer PP-g-MA and the reagents DER 671 and DEH 84 (solid state for both reagents). The liquid NBDA amine was incorporated with an external liquid pump at L/D $=17 \mathrm{D}$ of the extruder. For specific discussion as reported in the paragraph 4.1, the NBDA will be respectively injected at $L / D=32 \mathrm{D}$ and $\mathrm{L} / \mathrm{D}=42 \mathrm{D}$. The different formulations prepared are listed in Table 3. It is important to point out that all the formulations were carried out under stoichiometric conditions (an epoxy function for one amine proton or hydroxy proton) and that the number of moles of maleic anhydride (originating from PP-g-MA) is always in default relatively to the number of moles of $-\left[\mathrm{NH}_{2}\right] /-[\mathrm{NH}] /-[\mathrm{OH}]$. At the die of the extruder, the samples were cooled with air and granulated. The residence time in the extruder was estimated around $80 \mathrm{~s}$ from Ludovic Software ${ }^{\circledR}$. 
Table 3 : Mass fraction (wt $\%$ ) for each formulation

\begin{tabular}{|l|c|c|c|c|c|}
\hline \multicolumn{1}{|c|}{ Samples } & PPH3060 & PP-g-MA & DER671 & DEH84 & NBDA \\
\hline PP+20wt\%PP-g-MA & 80 & 20 & - & - & - \\
\hline $\begin{array}{l}\text { PP+20wt\% PP-g- } \\
\text { MA+26wt\%(DER671+DEH84) }\end{array}$ & 54 & 20 & 8.7 & 17.3 & - \\
\hline PP+26wt\%(DER671+DEH84) & 74 & - & 8.7 & 17.3 & - \\
\hline $\begin{array}{l}\text { PP+20wt\%+ PP-g-MA+12wt\% } \\
\text { (DER671+DEH84) }\end{array}$ & 68 & 20 & 4 & 8 & - \\
\hline $\begin{array}{l}\text { PP+9 wt\% PP-g-MA+12wt\% } \\
\text { (DER671+DEH84) }\end{array}$ & 79 & 9 & 4 & 8 & - \\
\hline $\begin{array}{l}\text { PP+15wt\% PP-g-MA+10wt\% } \\
\text { (DER671+NBDA) }\end{array}$ & 75 & 15 & 9.3 & - & 0.7 \\
\hline PP+10wt\% (DER671+NBDA) & 90 & - & 9.3 & - & 0.7 \\
\hline
\end{tabular}

\subsection{Soxhlet procedure}

In order to study the structures and chemical bonds created during the in situ synthesis of the epoxy based thermosetting phase in the PP by reactive extrusion, around $2 \mathrm{~g}$ of finely ground sample powder was placed in a thimble and then put in the Soxhlet apparatus. In the case of $\mathrm{PP}^{25,26}$, xylene is often adopted as the dissolution solvent under boiling conditions. In our experiment we used $250 \mathrm{~mL}$ of p-xylene (boiling point at $140{ }^{\circ} \mathrm{C}$ ). Once the first cycle began the reflux was maintained for at least $48 \mathrm{~h}$. Both the solid extracted and the soluble fraction were dried and weighed and further analyzed by DSC and Fourier-Transform Infrared Spectroscopy (FTIR). 


\section{CHARACTERIZATION}

\subsection{Tensile tests}

The formulations were injected into dumbbell specimens using a Babyplast 6/10P machine with a piston diameter of $14 \mathrm{~mm}$ and a clamping force of $62 \mathrm{kN}$. The temperature of the injection chamber was set between 200 and $220^{\circ} \mathrm{C}$ and the pressure between 80 and 100 bars depending on the viscosity of the formulation. At least five specimens from each sample were tested with an initial distance between the grips of $50 \mathrm{~mm}$. A speed of $5 \mathrm{~mm} \cdot \mathrm{min}^{-1}$ was used to strain the specimens in order to record the Young's modulus and $100 \mathrm{~mm} \cdot \mathrm{min}^{-1}$ for the elongation at break.

\subsection{Charpy Impact}

The impact strength of the different formulations was studied by means of a Charpy Impact test at room temperature. The formulations were injected into pieces with a width of $20 \mathrm{~mm}$, a length of $60 \mathrm{~mm}$ and a thickness of $10 \mathrm{~mm}$ using the same injection machine and conditions described above. A notch was realized at the center of the specimen $45^{\circ}$ wide and $2 \mathrm{~mm}$ deep. The impact test parameters were: mass $=0.917 \mathrm{~kg}$, pendulum length $=225 \mathrm{~mm}$, speed $=2.93$ $\mathrm{m} \cdot \mathrm{s}^{-1}$, fall angle $=150^{\circ}$ and fall height $=302 \mathrm{~mm}$.

\subsection{Transmission Electron Microscopy (TEM)}

Injected samples as described in section 3.1 were immerged in 1 wt $\% \mathrm{Ru}_{4}$ solution (water/sodium hypochlorite 50/50 : v/v) for $48 \mathrm{~h}$. Ultrathin samples (around $70 \mathrm{~nm}$ thick) were obtained by microtomy with an oscillating diamond knife at room temperature. The samples were placed in a copper grid and then positioned under vacuum into the column of the 
microscope (TEM PHILIPS CM120, CT $\mu$ Lyon, camera Gatan Orius200 2Kx2K) with an accelerating voltage of $120 \mathrm{kV}$.

\subsection{Differential Scanning Calorimetry (DSC)}

Melting temperature, melting enthalpy and degree of crystallinity were measured with a Differential Scanning Calorimetry (DSC) Q2000 machine (TA Instruments). In a hermetic aluminum capsules, $10 \mathrm{mg}$ of the different samples were placed and a temperature ramp was applied: a first heating step from $25^{\circ} \mathrm{C}$ to $250{ }^{\circ} \mathrm{C}$ at $10{ }^{\circ} \mathrm{C} \cdot \mathrm{min}^{-1}$ and a cooling step until room temperature at the same speed, the same procedure was repeated at least twice. It is possible to determine the degree of crystallinity of a polymer by differential scanning calorimetry by calculating the melting enthalpy $\left(\Delta \mathrm{H}_{\mathrm{m}}\right)$ and comparing this value to the melting enthalpy of a theoretical $100 \%$ crystalline $\operatorname{PP}\left(\Delta \mathrm{H}_{\mathrm{m} \infty}\right)$, as showed in the equation that follows:

$$
\% \text { Crystallinity }=\frac{\Delta H_{m}}{\Delta H_{m e d}} \times 100
$$

With $\Delta \mathrm{H}_{\mathrm{m} \infty}=200 \mathrm{~J} . \mathrm{g}^{-1} 27$

\subsection{X-rays Measurement (WAXS)}

X-rays scattering at wide angles (WAXS) were performed on $1 \mathrm{~mm}$ slices of a dumbbell specimen, injected such as described for the mechanical properties. The measurements were carried out at the Centre de Diffractométrie - CLEA in Lyon in transmission mode with an Oxford Gemini A Ultra diffractometer using a nickel filtered copper radiation (wave length = $0.154 \mathrm{~nm}$ ). The WAXS analyses allow us to study the different crystalline phases present in the PP. The PP used here presents at first only $\alpha$ form crystals. 


\subsection{Fourier-Transform Infrared Spectroscopy (FTIR)}

The infrared transmission spectra of solid samples were obtained thanks to Smart OMNI transmission (Thermo Fischer Scientific, 64 scans). A film (with a thickness between 30 and 40 $\mu \mathrm{m})$ was prepared under hot press at $200^{\circ} \mathrm{C}$ for each sample.

\section{RESULTS AND DISCUSSION}

\subsection{Epoxy based thermosetting synthesis and chemical mechanisms}

Figure 2 shows the morphology of the reactive blend PP+26wt\%(DER671+DEH84) (A) and $\mathrm{PP}+20 \mathrm{wt} \% \mathrm{PP}-\mathrm{g}-\mathrm{MA}+26 \mathrm{wt} \%(\mathrm{DER} 671+\mathrm{DEH} 84)(\mathrm{B})$. The aim here is to evidence the important role of the compatibilizer in the final morphology.

Actually, the importance of a compatibilizer ${ }^{28,29}$ and its consequences on the final morphology in non-miscible polymer blends has been demonstrated in numerous publications. Figure 2-A, without PP-g-MA, shows a larger TS size dispersion with nodules with diameters up to $5 \mu \mathrm{m}$. In Figure 2-B, the TS domains are almost not identifiable because of low magnification applied. Thanks to complementary TEM analysis, we observe that for the sample without PP-gMA (TEM A), the diameter of the TS particles is superior to $3 \mu \mathrm{m}$. However, on the micrograph for the compatibilized sample (TEM B) we can clearly identify smaller TS domains. We have a narrower distribution, several nodules of $0.5 \mu \mathrm{m}$ diameter and even smaller nodules with the presence of PP-g-MA as compatibilizer are observed. The creation of these small domains thanks to PP-g-MA decreases the interfacial tension between the nodules and the PP matrix and tends towards a more stable and finer morphology. Note that the same type of morphology is observed for the blends with NBDA [SI-1]. 

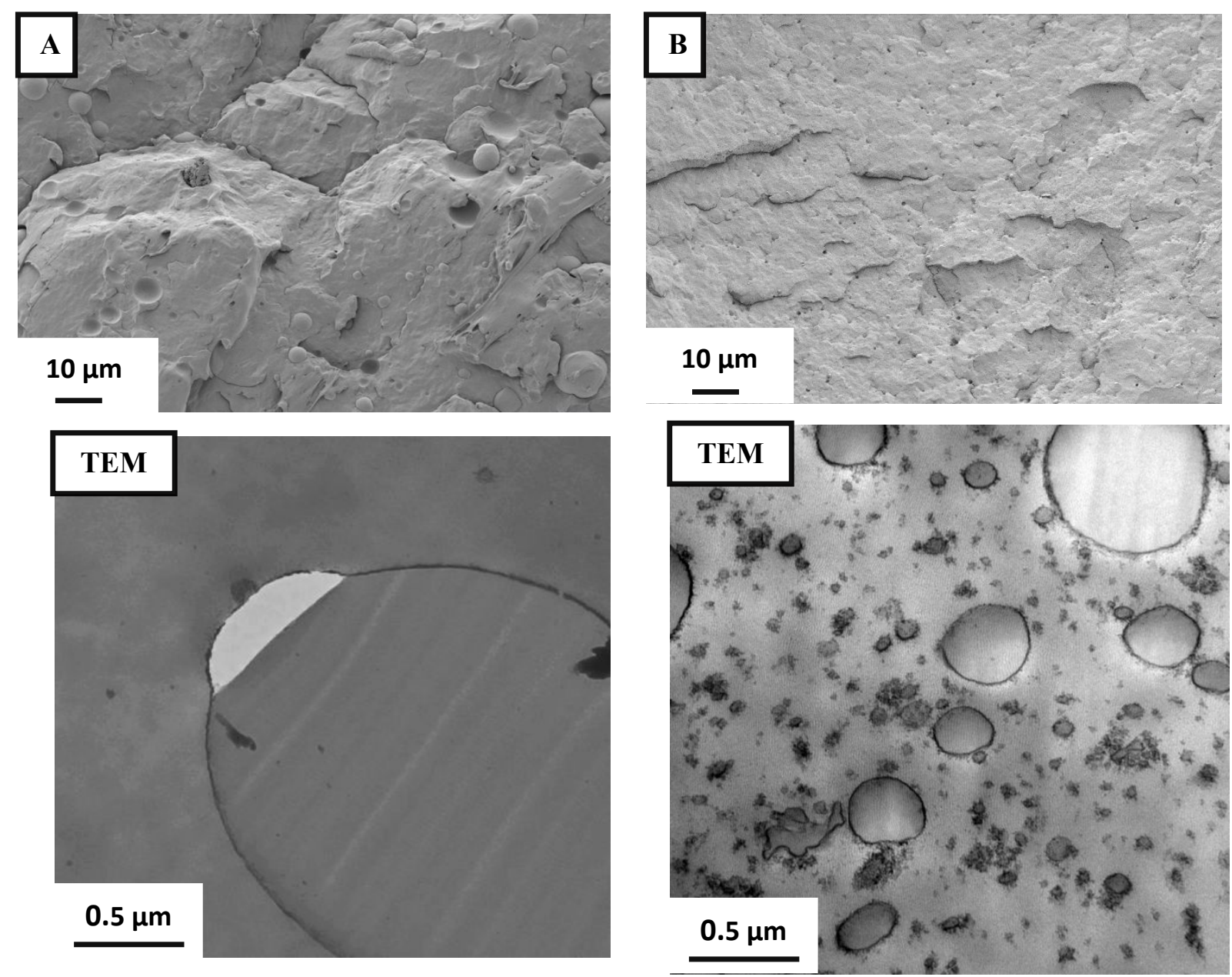

Figure 2 : SEM micrograph of PP+26\%wt(DER671+DEH84) (A) and PP+20wt\%PP-g$\mathrm{MA}+26 \% \mathrm{wt}(\mathrm{DER} 671+\mathrm{DEH} 84)(\mathrm{B})$ and respective corresponding TEM micrograph (formulations stained with $\mathrm{RuO}_{4}$ )

Mazidi $^{30}$ et al., studied the impact of EPDM grafted with maleic anhydride (mEPDM) as a compatibilizer in a PP (matrix)/PA6 blend. The microstructure of the ternary blend is very similar to the one observed for our system, with a dispersed phase with a diameter inferior to the micron and with a thin interface between the two polymers, and they were able to measure the interfacial tension between PP/PA6, PP/mEPDM and PA6/mEPDM. The values at $230^{\circ} \mathrm{C}$ are around $5 \mathrm{mN} \cdot \mathrm{m}^{-1}$ for the blends with $\mathrm{mEPDM}$ and almost three times higher for pure PP/PA6 blends. Thus, the presence of a compatibilizer significatively reduces the interfacial tension between two immiscible polymers. 
$\mathrm{Hu}^{31}$ et al. also demonstrated the importance of a compatibilizer in the final morphology. In fact, during in situ synthesis of a PA6 in a PP matrix by reactive extrusion, 3-isopropenyl-R,Rdimethylbenzene isocyanate (TMI) grafted onto PP (PP-g-TMI) is introduced. PP-g-TMI initiated the creation of a copolymer PP-g-PA6 created simultaneously with the PA-6 synthesis and leads to its nanostructuration, with $80 \mathrm{~nm}$ diameter PA6 nodules.

In our case, this compatibilization can be explained by the creation of a chemical bond between PP-g-MA and the epoxy based thermosetting phase (one possible reaction is reported on the Figure 3). In order to qualify and quantify the nature of the minor phase/interface created, a Soxhlet extraction was carried out to separate the matrix from the TS based-phase.

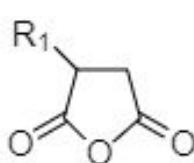<smiles>[R]N</smiles>
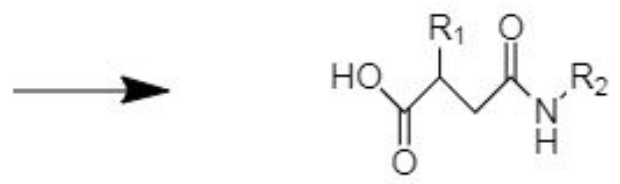

Figure 3 : One possible chemical reaction between PP-g-MA and the amine reactant for DER671/NBDA system

First, we evaluated the Soxhlet efficiency on the systems without PP-g-MA. Therefore, the PP from non-compatibilized formulations PP+26wt\%(DER671/DEH84) and $\mathrm{PP}+10 \mathrm{wt} \%$ (DER671/NBDA) were selectively extracted by xylene. For both formulations, 95 wt $\%$ of the PP was extracted evidencing the efficiency of the solvent chosen ${ }^{32}$ with uncertainty estimated to be $5 \%$. This same uncertainty was observed by Bream and Hornsby ${ }^{33}$ during a Soxhlet extraction of PP/PP-g-MA in xylene.

These results were confirmed by DSC analysis as shown in Figure $\mathbf{4}$ for PP+26wt\%(DER671/DEH84) before (black curve) and after extraction (red curve). In both cases, we can observe a signal at $165^{\circ} \mathrm{C}$ corresponding to the $\mathrm{PP}$ melting and a signal at $75^{\circ} \mathrm{C}$ on the red curve corresponding to the $\mathrm{T}_{\mathrm{g}}$ of the TS created. The melting signal corresponding to the 
insoluble fraction after extraction has a lower intensity, confirming that the amount of PP was drastically reduced after extraction. The soluble part was also analyzed after solvent evaporation and the mass balance showed that almost all the PP was solubilized in the xylene.

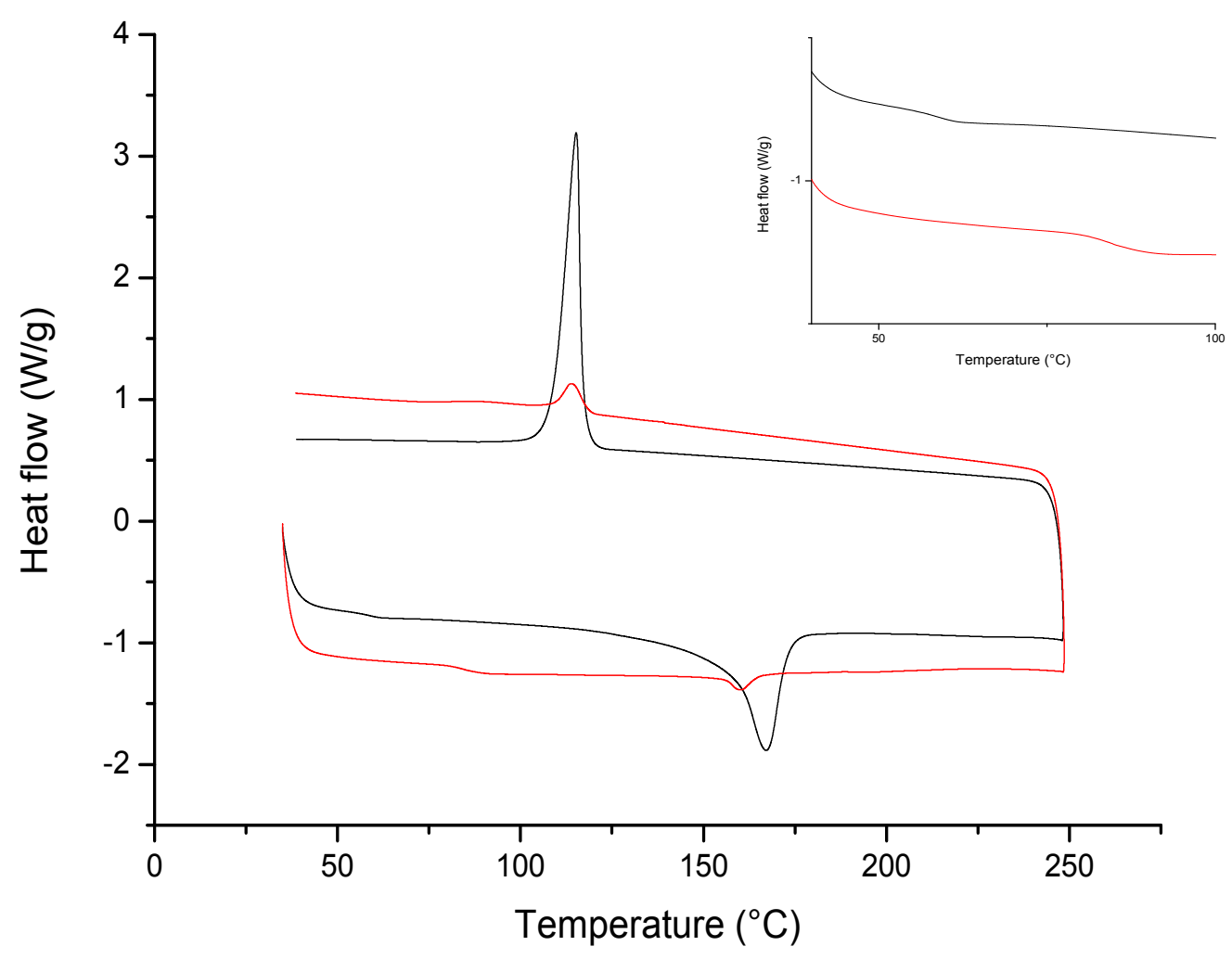

Figure 4: DSC analysis of the initial sample PP+26 wt\%(DER671+DEH84) (black) and of the insoluble fraction after Soxhlet extraction (red)

Infrared analyses were also carried out. In Figure 5, we can observe the FTIR spectra for the sample PP+26wt\%(DER671+DEH84) before (black) and after (red) Soxhlet extraction and the DER671+DEH84 based-TS system (blue). Signals corresponding to the aromatic cycles vibrations from the DER 671 and DEH84 can be observed between 1450 and $1750 \mathrm{~cm}^{-1}$. We can also observe signals corresponding to the stretch of C-O bonds visible at 1060 and $1220 \mathrm{~cm}^{-1}$. Finally, the spectra present signals at $3000 \mathrm{~cm}^{-1}$ corresponding to the $-\mathrm{CH},-\mathrm{CH}_{2}$ and $-\mathrm{CH}_{3}$ elongations vibrations, therefore corresponding to the carbon chain of the DER 671 and the PP. These signals are more intense on the spectrum for the sample before extraction than on the one 
the corresponding to the sample after the Soxhlet procedure due to the fact that most of PP was extracted. The spectra also show the corresponding signals of the pure TS system (blue). As we can notice, the signals corresponding to the $-\mathrm{CH},-\mathrm{CH}_{2}$ bonds are even less intense on the spectrum for this sample than on the one for the sample after extraction, showing that a small amount of PP is trapped in the insoluble part and not only the $-\mathrm{CH},-\mathrm{CH}_{2}$ corresponding to the TS are present in the sample.
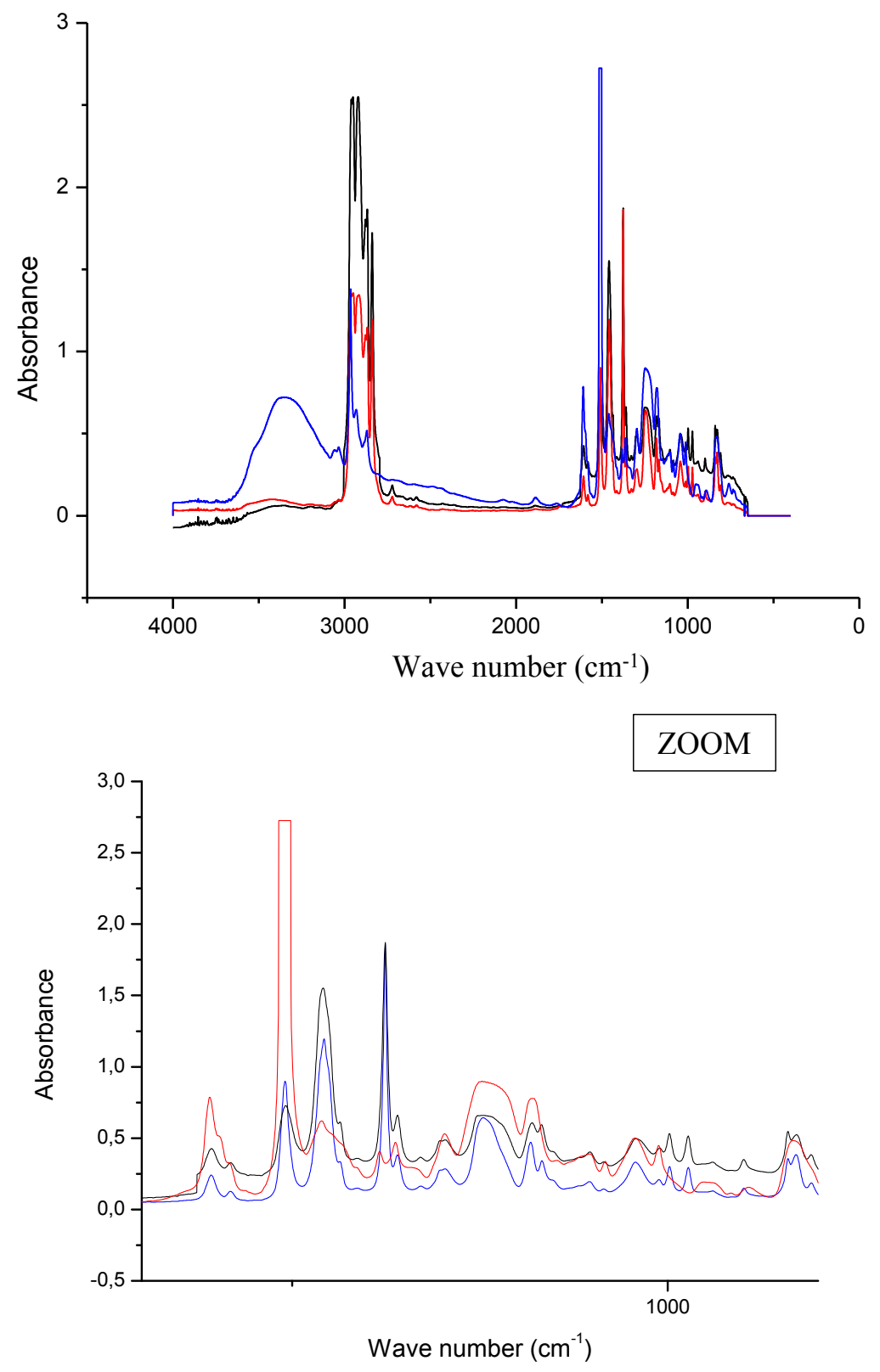

Figure 5 : FTIR spectra of PP+26wt\%(DER671+DEH84) before (black), after (red) Soxhlet extraction and the TS system DER671+DEH84 (blue), standard calibration with the peak at $1400 \mathrm{~cm}^{-1}$. 
The same procedure was applied to the formulations containing PP-g-MA: PP+20wt\%PP-g$\mathrm{MA}+26 \mathrm{wt} \%(\mathrm{DER} 671 / \mathrm{DEH} 84)$ and PP+15wt\%PP-g-MA+10wt\%(DER671/NBDA). Thanks to the mass balance (Table 4) we observe that, for the sample containing the DEH $84,60 \mathrm{wt} \%$ of the total mass of the sample is insoluble and could not be extracted by the xylene. In fact, assuming that all PP-g-MA was consumed in order to create the interface component with the TS, we should theoretically obtain only $46 \mathrm{wt} \%$ of insoluble fraction (TS+PP-g-MA). Therefore, not all the PP was extracted. In Figure 6, both DSC thermograms for the samples before and after Soxhlet extraction present a melting signal associated to PP/PP-g-MA at $165^{\circ} \mathrm{C}$. The $\mathrm{T}_{\mathrm{g}}$ of the $\mathrm{TS}$ at $65^{\circ} \mathrm{C}$ is only visible on the thermogram for the sample after extraction since it is more concentrated in TS. We can then conclude that the TS, the PP-g-MA and a part of the PP could not be dissolved in the xylene. The DSC of the soluble part, which is mainly composed of PP after evaporation of the solvent, was realized. As expected, the curve obtained for this sample is exactly like the one for the single PP [SI-2] but with crystallinity degree around $35 \%$ instead of $42 \%$ for pure PP. For the sample composed of NBDA, the same scenario is observed but with $45 \mathrm{wt} \%$ of insoluble fraction instead of $25 \%$ in theory (PP-gMA+TS). Consequently, 20\% of the PP could not be extracted in our experimental conditions and it is trapped in the thimble (Table 4).

Table 4: Mass balance (wt\%) after extraction of PP by Soxhlet in a ternary blend PP/PP-g$\mathrm{MA} / \mathrm{TS}$

\begin{tabular}{|l|c|c|c|c|c|}
\hline \multicolumn{1}{|c|}{ Samples } & PP-g-MA & TS & $\begin{array}{c}\text { Insoluble } \\
\text { (theoretical) }\end{array}$ & $\begin{array}{c}\text { Insoluble } \\
\text { (experimental) }\end{array}$ & PP trapped \\
\hline $\begin{array}{l}\text { PP+20wt\%PP-g- } \\
\text { MA+26wt\%(DER671/DEH84) }\end{array}$ & 20 & 26 & 46 & 60 & 14 \\
\hline $\begin{array}{l}\text { PP+15wt\%PP-g- } \\
\text { MA+10wt\%(DER671/NBDA) }\end{array}$ & 15 & 10 & 25 & 45 & 20 \\
\hline
\end{tabular}




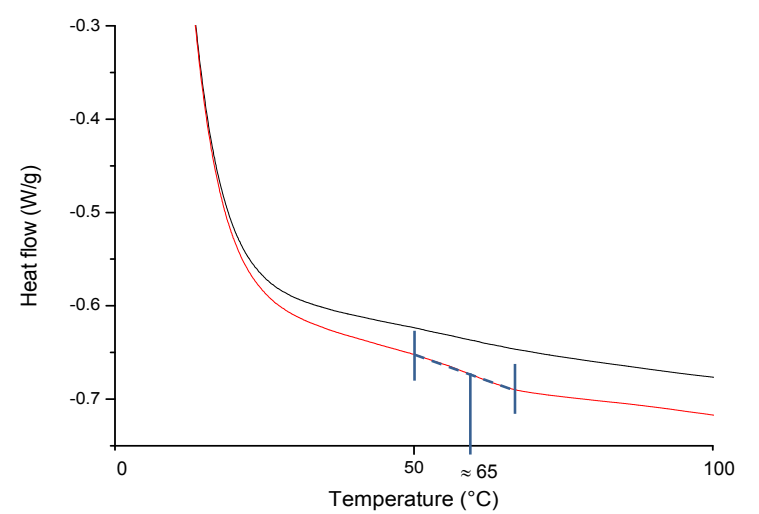

Figure 6 : DSC analysis of PP+20wt\%PP-g-MA $+26 \mathrm{wt} \%(\mathrm{DER} 671+\mathrm{DEH} 84)$ before (black) and after Soxhlet extraction (red)

The FTIR spectra for the sample PP+20wt $\%$ PP-g-MA+26wt $\%($ DER671+DEH84) before and after Soxhlet extraction was also realized. As described before, the signals corresponding to the TS phase with the $-\mathrm{C}-\mathrm{O}$ stretch (at 1060 and $1220 \mathrm{~cm}^{-1}$ ) and the aromatic cycles vibrations (between 1450 and $1750 \mathrm{~cm}^{-1}$ ) are visible. We can also observe the signals corresponding to the $-\mathrm{CH},-\mathrm{CH}_{2},-\mathrm{CH}_{3}$ around $3000 \mathrm{~cm}^{-1}$. As expected, these peaks are less intense on the spectrum for the sample after extraction. In fact, since most of PP was extracted the peaks corresponding to the $-\mathrm{CH},-\mathrm{CH}_{2},-\mathrm{CH}_{3}$ bonds are mostly from the TS sample, therefore are less intense [SI-3].

The Soxhlet extractions and the chemical analysis carried out allowed us to conclude that a covalent bond between the TS and the matrix PP/ PP-g-MA was created. In fact, thanks to the mass balance we can see that after extraction not only the mass of PP-g-MA + TS was insoluble but also around $25 \mathrm{wt} \%$ (Table 4) of the total mass of the PP. We can than assume that all the 
maleic anhydride from the PP-g-MA was consumed in order to create the interfacial component PP-g-TS.

The role of the compatibilizer was proved to be essential in the morphology of the blend and to have great influence in the chemical bonds of the material. It is now important to analyze how the TS was created in the PP molten state.

This part is dedicated to understand how the epoxy based thermosetting is in situ created in the PP matrix during the reactive extrusion and the role of the quite high concentration of the PP-gMA. In order to argue this point, a complementary experiment was carried out, where the amine (NBDA) was introduced at respectively at $\mathrm{L} / \mathrm{D}=17 \mathrm{D}, 32 \mathrm{D}$ and $42 \mathrm{D}$ (Figure 1). TEM micrographs were observed to understand the evolution of the morphology.

In Figure 7-A, the morphology of PP+15wt\%PP-g-MA+10wt \%(DER671+NBDA) where NBDA is injected at $\mathrm{L} / \mathrm{D}=45 \mathrm{D}$ is observed. Therefore, the reaction time between DER671 and NBDA will be quite short, around $10 \mathrm{~s}$ only. Even though the reaction time is limited, the conversion in TS can be considered to be complete. Actually, the kinetics' reaction of the TS (DER671+NBDA) was measured and the gel point is obtained at $200^{\circ} \mathrm{C}$ in less than $1 \mathrm{~s}$. In Figure 7-A, we observe TS domains of $0.5 \mu \mathrm{m}$ diameter with a thin interface between the two phases, smaller domains are also observed and are, for most of them, scattered in the matrix (blue circle). The Figure 7-B depicts the morphology obtained for the same formulation as A, but with NBDA injected at $\mathrm{L} / \mathrm{D}=32 \mathrm{D}$. Once more, we observe TS nodules of on average 0.5 $\mu \mathrm{m}$ of diameter and well dispersed in the matrix, though the domains are less visible in the matrix and seem to be in small aggregates. In this case, the reaction time in the extruder is around 30 s. Figure 7-C depicts the morphology for the same formulation as before but with NBDA injected at the beginning of the extruder, at $\mathrm{L} / \mathrm{D}=15 \mathrm{D}$, so in this case the reaction time between DER671 and the NBDA will be around one minute. The morphology of the sample is 
very similar to the two previous one, the nodules have an average diameter of $0.5 \mu \mathrm{m}$ and the interface seems thin and clear between the two domains. Nevertheless, smaller domains are also observed and are aggregated around the bigger nodules (blue circle). By comparing the Figure 7-A and 7-C, we can conclude that the repartition of the domains in the matrix is different and can be analyzed as the evolution of the morphology versus times of reaction. In the Figure 7-A, the smaller domains are dispersed in the matrix whereas in the Figure 7-C, they are aggregated around the bigger nodules. In fact, the earlier the NBDA is introduced, the more packed around the TS nodules the domains seem to be, letting us imagine that for a longer residence time in the extruder the domains are aggregating to the TS nodules. On the micrograph reported in the Figure 8 at a smaller scale, this phenomenon is clearly evidenced, where small domains are all around the bigger TS nodules in the sample PP+10wt\% PP-g-MA+15wt\%(DER671+NBDA) with NBDA injected at 15D.

The DSC analyses of the three formulations were carried out and the point of injection of the NBDA has no influence in the crystallinity, melting point nor $T_{g}$ of the sample [SI-4].

Recently, Oyama ${ }^{34}$ et al. observed similar phenomenon for a blend composed of PP matrix, with poly(ether sulfone) (PES) nodules with a PP grafted with glycidyl methacrylate as compatibilizer (mPP). In fact, the smaller nodules were found to be mPP/PES copolymers that avoid the coalescence between the PES nodules.

This experiment allowed us to conclude that the reaction time between NBDA and DER 671 has an impact in the final morphology of the blend. We observed two populations of domains corresponding to the minor phase: large nodules and small domains which are aggregating to the larger ones with longer residence times in the extruder. 

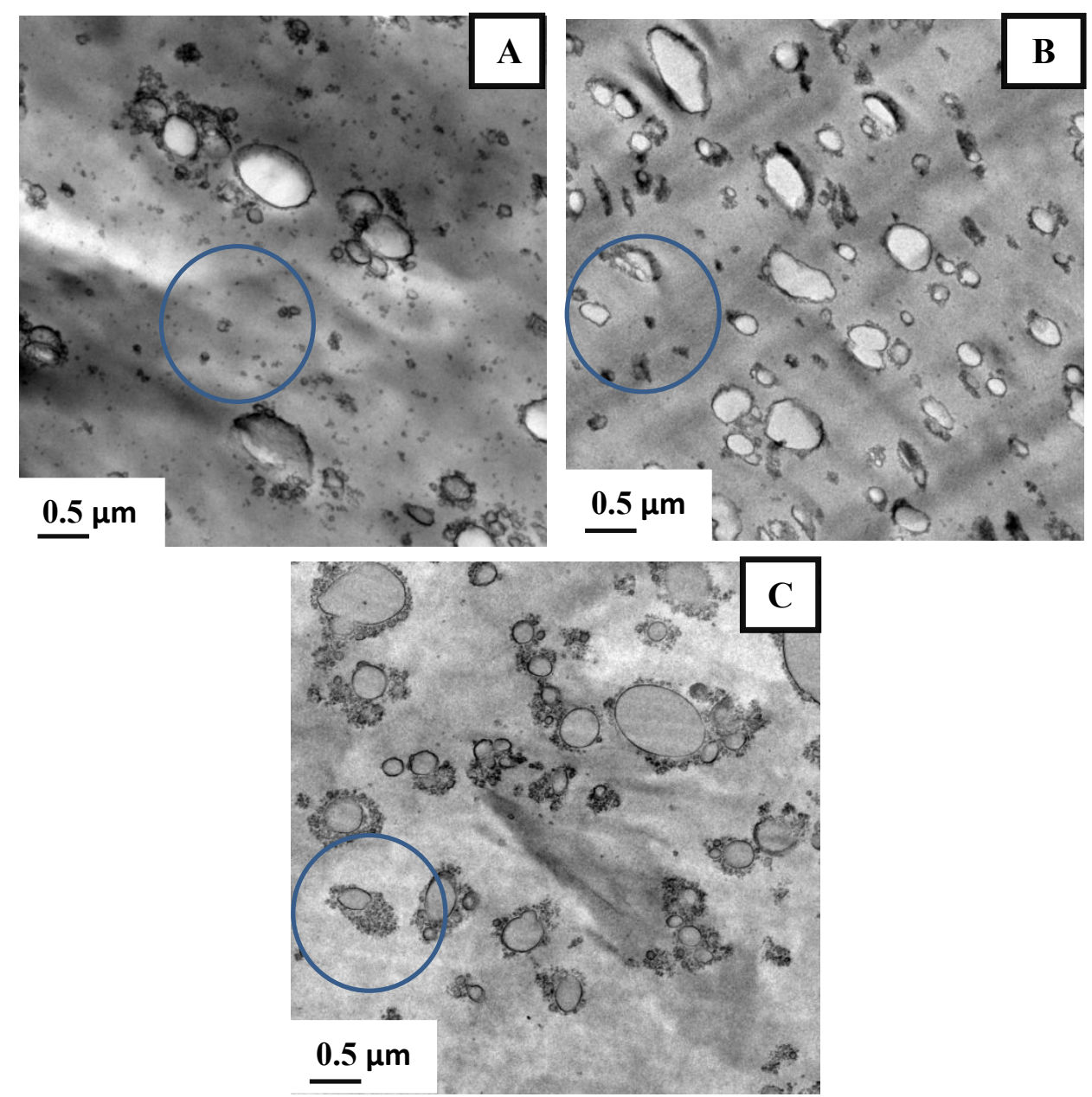

Figure 7: TEM micrographs of PP+15 wt\% PP-g-MA+10 wt $\%$ (DER671+NBDA) with NBDA injected at (A) 45D, (B) 30D and (C) 15D.

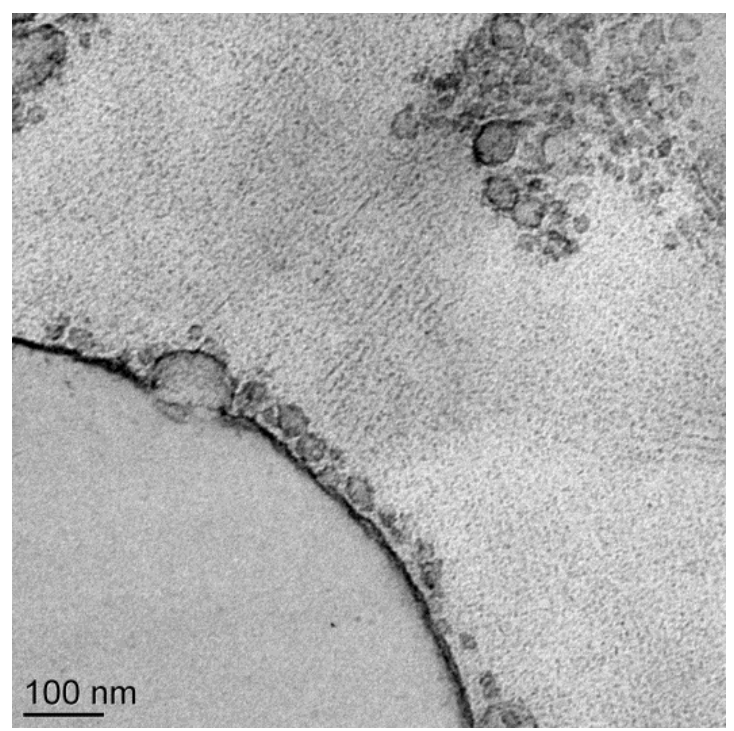

Figure 8 : TEM micrograph of PP+10 wt $\%$ PP-g-MA+15wt\%(DER671+NBDA) with NBDA injected at $\mathrm{L} / \mathrm{D}=15 \mathrm{D}$

\subsection{Degree of crystallinity and crystalline structure}


DSC analyses allow us to calculate the crystallinity of the blends thanks to the melting signal. The PP pure has crystallinity degree of $42 \%$ and this amount is increased with the presence of PP-g-MA. In order to obtain the crystallinity related to the amount of matrix present in the sample, the crystallinities listed on Table 5 refer directly to the mass of PP+ PP-g-MA. The crystallinity of the matrix decreases in the presence of TS. For the PP+20wt\%PP-g-MA $+26 \mathrm{wt} \%$ (DER671+DEH84) blend, the crystallinity is of 30\%, the lowest crystallinity degree for the highest amount of PP-g-MA and TS. This phenomenon is observed for the both nature of TS created and could be correlated to its concentration.

Table 5 : Crystallinity degree of the polyolefins part determined by DSC

\begin{tabular}{|l|c|}
\hline \multicolumn{1}{|c|}{ Samples } & \% Crystallinity \\
\hline PPH3060 & 42 \\
\hline PP+20wt\%PP-g-MA & 46 \\
\hline PP+20wt\% PP-g-MA +26wt\%(DER671+DEH84) & 30 \\
\hline PP+9wt\% PP-g-MA +12wt\%(DER671+DEH84) & 36 \\
\hline PP+15wt\% PP-g-MA +10wt\%(DER671+NBDA) & 35 \\
\hline
\end{tabular}

A specific study by WAXS was carried out in order to understand the influence of the creation of TS on the PP crystalline structure. Figure 9 shows the WAXS patterns for the samples PP, $\mathrm{PP}+20 \mathrm{wt} \%$ PP-g-MA, PP+15wt\% PP-g-MA +10wt\%(DER671+NBDA) and PP+20wt\% PP-g$\mathrm{MA}+26 \mathrm{wt} \%(\mathrm{DER} 671+\mathrm{DEH} 84)$. The peaks are assigned to the $\alpha$ and $\beta$ crystalline phases of the $\mathrm{PP}^{35}$. The samples containing only PP and PP-g-MA evidenced peaks corresponding to $\alpha$ phase, the crystals in these samples are $100 \%$ under $\alpha$ form, the most stable phase. We can observe the characteristics $\alpha$ peaks corresponding to the plans $(110)$ at $15^{\circ}$ and $22^{\circ},(040)$ at $18^{\circ}$ and (130) at $20^{\circ}$. In the presence of TS, we can observe a new peak around $17^{\circ}$ corresponding to the appearance of the $\beta$-phase (300) of $\mathrm{PP}^{21}$. In fact, in Figure 9-A, we can observe that the 
peak corresponding to the $\beta$-phase appears as a shoulder, the sample containing $10 \mathrm{wt} \%$ of TS. In Figure 9-B the peak is more intense and clearer as the sample contains $26 \mathrm{wt} \%$ of TS. By comparing both systems, it is clearly shown that its intensity is related to the concentration of TS created.

Recently, $\mathrm{Liu}^{36}$ et al. showed that the amount of $\beta$-nucleating agent and the quantity of $\beta$-phase is related for PP matrix and poly(Acrylonitrile-Butadiene-Styrene) (ABS) as a minority phase. In fact, the more $\beta$-nucleating agent is introduced; the more $\beta$-phase crystals will appear. However, at some point a maximum is reach $(1 \mathrm{wt} \%$ for $\mathrm{ABS}$ in PP). Our results confirm this tendency. 

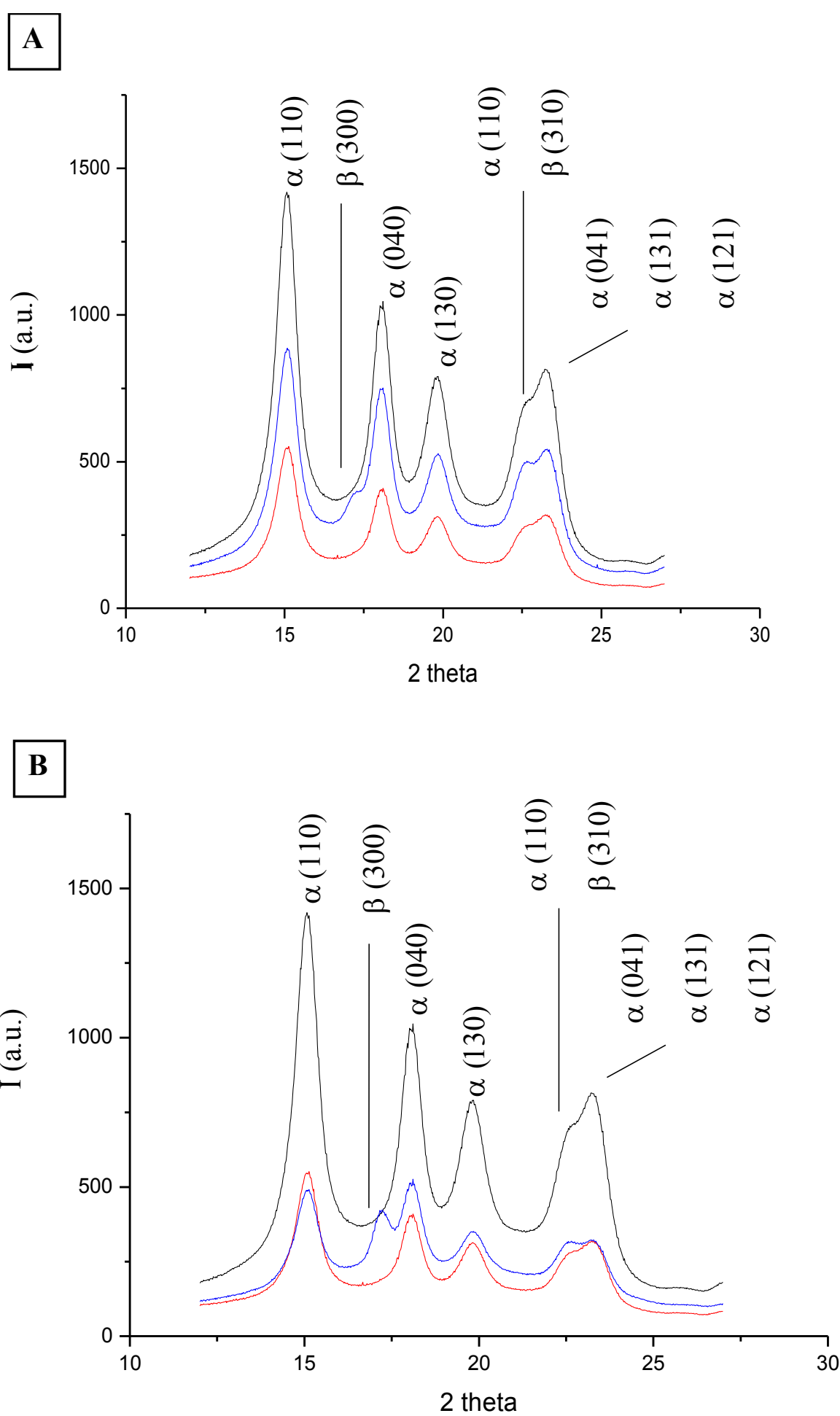

Figure 9 : XRD patterns of PP (black), PP+20wt $\% \mathrm{PP}-\mathrm{g}-\mathrm{MA}($ red) and $\mathrm{PP}+15 \mathrm{wt} \% \mathrm{PP}-\mathrm{g}-$ $\mathrm{MA}+10 \mathrm{wt} \%$ (DER671+NBDA) (A-blue) and PP+20wt\%PP-g-MA+26wt\%(DER671+DEH84) (B-blue)

The presence of PP-g-MA as a compatibilizer will not only have an influence on the morphology and on mechanical properties, but also on crystalline structure which will itself 
have an influence on the mechanical properties. Figure 10 reports WAXS diffractograms obtained for two samples with and without PP-g-MA. The black curve corresponds to the response for the $\mathrm{PP}+26 \mathrm{wt} \%(\mathrm{DER} 671+\mathrm{DEH} 84)$ sample. It can be seen a light shoulder around $17^{\circ}$ where the plan (300) corresponding to a $\beta$-form should be. On the other hand, the red curve, obtained with the sample containing $20 \mathrm{wt} \%$ of PP-g-MA, we have a distinguished peak at this angle, letting us believe that not only the presence of TS generates a $\beta$-phase but also the compatibilization between the TS nodules and the PP matrix, therefore the presence of the interface component PP-g-TS. The same behavior was observed for the samples with NBDA [SI-5].

This same phenomenon was observed by $\operatorname{Lin}^{37}$ et al. for a PP/Polyamide 6 (PA6) blend. This study was carried with a PP with high content of $\beta$-phase, since it was nucleated by calcium carbonate $\left(\mathrm{CaCO}_{3}\right)$. WAXS patterns show that $\beta$-PP/PA6 blends have less $\beta$-form than $\beta$ PP/PA6/PP-g-MA blends. In fact, the absence of a compatibilizer will increase the interfacial tension between the two polymers, decrease the package effect and inhibit the $\beta$-crystallization effect on PP. Thus, it was possible to have high content of $\beta$-crystals in a $\beta$-PP/PA6/PP-g-MA by controlling the proportions of PP-g-MA.

The compatibilizer will therefore play an important part in the amount of $\beta$ phase generated during the synthesis by reactive extrusion of PP/PP-g-MA/TS blends. 


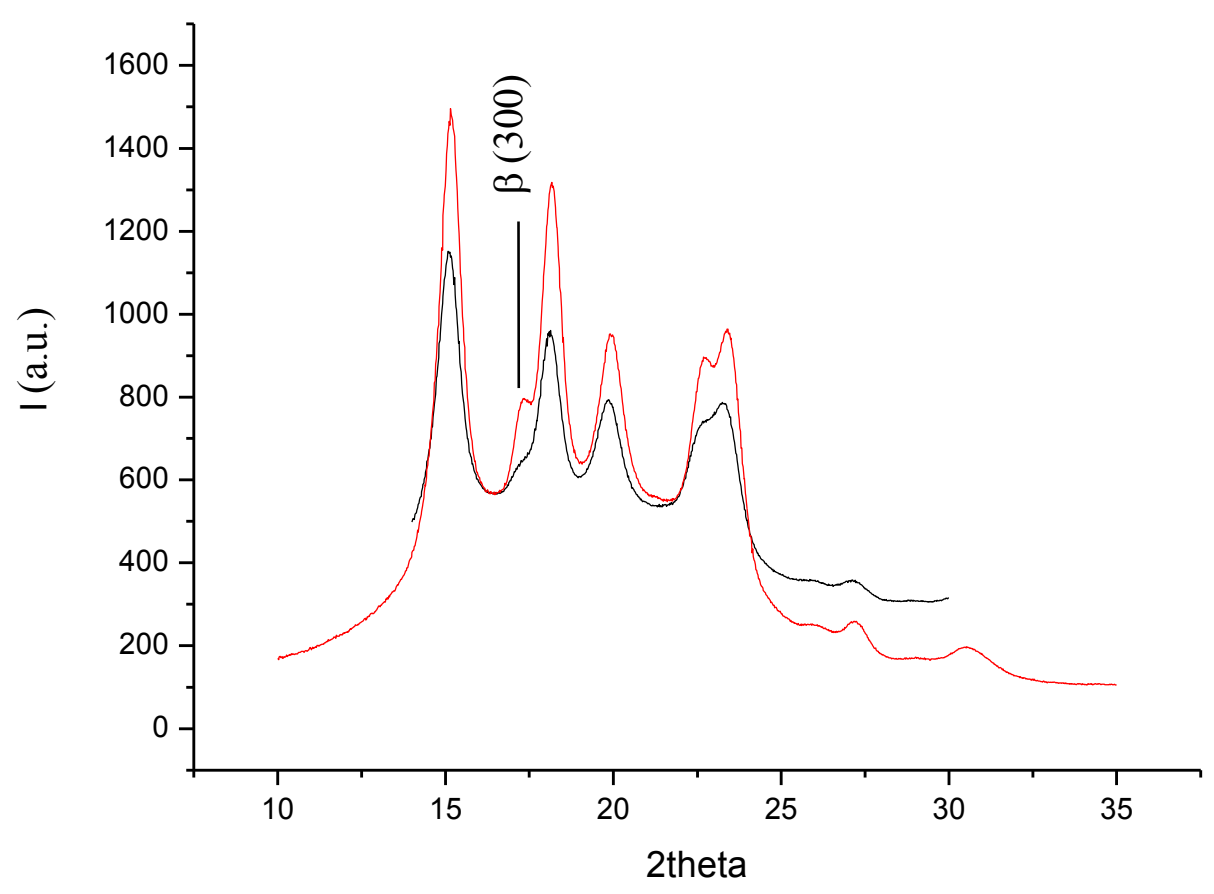

Figure 10 : XRD patterns of PP+26wt\%(DER671+DEH84) (black) and PP+20wt\%PP-g$\mathrm{MA}+26 \mathrm{wt} \%(\mathrm{DER} 671+\mathrm{DEH} 84)$ (red)

\subsection{Mechanical properties}

The mechanical properties are intimately related to the morphology and the crystallinity structure of a polymer blend. Indeed, since most of polymers blends are immiscible, the presence of nodules of different nature of the matrix can lead to defects that can have negative impacts in the tensile and impact strength and in the elongation at break. In this part we intend to elucidate the role of the creation of the epoxy based thermosetting phase, the PP-g-MA and the modification of crystalline structure on the mechanical properties.

In order to understand the effects of the compatibilizer in a macroscopic point of view, the tensile properties for both formulations studied before were investigated.

The tensile properties for the all the formulations are listed in Table 6. 
Table 6 : Mechanical properties for PPH3060, PP+26 wt\%(DER671+DEH84), PP+20wt\% PPg-MA+26wt $\%($ DER671+DEH84), $\quad \mathrm{PP}+10 \mathrm{wt} \%(\mathrm{DER} 671+\mathrm{NBDA}) \quad$ and $\mathrm{PP}+15 \mathrm{wt} \%$ PP-g$\mathrm{MA}+10 \mathrm{wt} \%(\mathrm{DER} 671+\mathrm{NBDA})$

\begin{tabular}{|c|c|c|c|c|}
\hline Samples & $\begin{array}{l}\text { Young's } \\
\text { Modulus (MPa) }\end{array}$ & $\begin{array}{l}\sigma_{\text {break }} \\
(\mathrm{MPa})\end{array}$ & $\begin{array}{l}\text { Elongation at } \\
\text { break }(\%)\end{array}$ & $\operatorname{Re}\left(\mathrm{kJ} \cdot \mathrm{m}^{-2}\right)$ \\
\hline PPH3060 & 1640 & 20 & 40 & $6.5 \pm 0.6$ \\
\hline $\mathrm{PP}+20 \mathrm{wt} \% \mathrm{PP}-\mathrm{g}-\mathrm{MA}$ & 1600 & 18 & 120 & $4.2 \pm 0.8$ \\
\hline $\mathrm{PP}+26 \mathrm{wt} \%(\mathrm{DER} 671+\mathrm{DEH} 84)$ & 2000 & 30 & 2 & $2.5 \pm 0.6$ \\
\hline $\begin{array}{l}\mathrm{PP}+20 w t \% \text { PP-g-MA } \\
+26 \mathrm{wt} \%(\text { DER671+DEH84) }\end{array}$ & 2030 & 18 & 50 & $7.5 \pm 0.4$ \\
\hline $\mathrm{PP}+10 \mathrm{wt} \%(\mathrm{DER} 671+\mathrm{NBDA})$ & 1700 & 20 & 22 & $3.8 \pm 0.5$ \\
\hline $\begin{array}{l}\mathrm{PP}+15 w t \% P P-g-M A \\
+10 w t \%(D E R 671+N B D A)\end{array}$ & 1850 & 20 & 50 & $9.4 \pm 0.7$ \\
\hline
\end{tabular}

As we can see, the Young's modulus of the four formulations with TS are increased, 23\% for the formulation PP+20wt\% PP-g-MA+26wt\%(DER671+DEH84) and 14\% for PP+15wt\%PPg-MA+10wt $\%$ (DER671+NBDA); the epoxy based thermosetting created in situ therefore affect positively this property. The introduction of thermosets in a thermoplastic matrix tends to create materials with good mechanical properties. Fine and Pascault ${ }^{38}$ showed the increase of mechanical properties for poly(phenylene ether) (PPE) and a thermoset reactive blend which is controlled by the compatibilizer, a triblock poly(styrene-b-butadiene-b-methyl methacrylate) (SBM) and the morphology that is consequently created.

The role of PP-g-MA in the morphology was described before. Its presence also has a positive impact in the elongation at break.

In fact, as we can see Table 6, the elongation at break decrease drastically depending of the presence of the compatibilizer or not, going from $50 \%$ for the $\mathrm{PP}+20 \mathrm{wt} \% \mathrm{PP}-\mathrm{g}$ $\mathrm{MA}+26 \mathrm{wt} \%$ (DER671+DEH84) sample down to 2\% for PP+26wt\%(DER671+DEH84) sample. 
The poor interface between the TS nodule and the PP matrix in this last case is classically at the origin of such observation.

Another characteristic that will have an important role in the mechanical properties is the crystallinity structure of the blend. It is well known that $\beta$-phase has important consequences in mechanical properties, especially in reinforcing the resilience of the material ${ }^{20,21}$. In fact, $\mathrm{Xu}^{39}$ et al. showed that the spherulites in PP due to the $\beta$-phase were intercrossed by several fibrils, letting us believe that molecules intra and inter spherulite are linked. In our case, the presence of interface component PP-g-TS will reinforce this behavior.

Table 6 also shows the results of impact tests for samples with and without compatibilizer. We can see that the resilience increases for samples with PP-g-MA, therefore with PP-g-TS, going from 2.5 to $7.5 \mathrm{KJ} . \mathrm{m}^{-2}$ for the samples with DER 671+DEH 84, for example.

Two main factors contribute to these results:

- With the compatibilizer the blend presents improved mechanical properties due to the control of interfacial adhesion ${ }^{29}$

- The presence of PP-g-MA and the TS will also lead to a $\beta$-phase in the sample, major factor in the improvement of the resilience ${ }^{20,21}$

In order to prove that the increase of the resilience is mostly due to the $\beta$-phase created by the formation of the TS, a last test was carried out. In fact, the samples that presented an important quantity of $\beta$-phase $(\mathrm{PP}+20 \mathrm{wt} \% \mathrm{PP}-\mathrm{g}-\mathrm{MA}+26 \mathrm{wt} \%(\mathrm{DER} 671+\mathrm{DEH} 84)$ and $\mathrm{PP}+15 \mathrm{wt} \% \mathrm{PP}-\mathrm{g}-$ $\mathrm{MA}+10 \mathrm{wt} \%$ (DER671+NBDA)) were annealed at $135{ }^{\circ} \mathrm{C}$ for $12 \mathrm{~h}$ in an oven. In fact, the melting temperature of the $\beta$-PP is known to be lower than the $\alpha-\mathrm{PP}^{33}$ (around $135^{\circ} \mathrm{C}$ instead $165^{\circ} \mathrm{C}$ for the $\left.\alpha-\mathrm{PP}\right)$. The goal is to melt only the $\beta$-phase of the matrix, so that it can 
recrystallize into an $\alpha$ conformation, so that only $\alpha$-phase will be present in the sample ${ }^{40}$. The complete elimination of the $\beta$-crystallinity was observed by WAXS (Figure 11), as we can see the black curve does not present anymore shoulder or peak at $17^{\circ}$, whereas for the same sample without thermal treatment a shoulder is clearly visible (red curve).

Once the crystalline structure was defined, the resilience tests were carried out. The mechanical properties associated to the annealed samples are listed in Table 7 and compared to the ones for the initial samples.

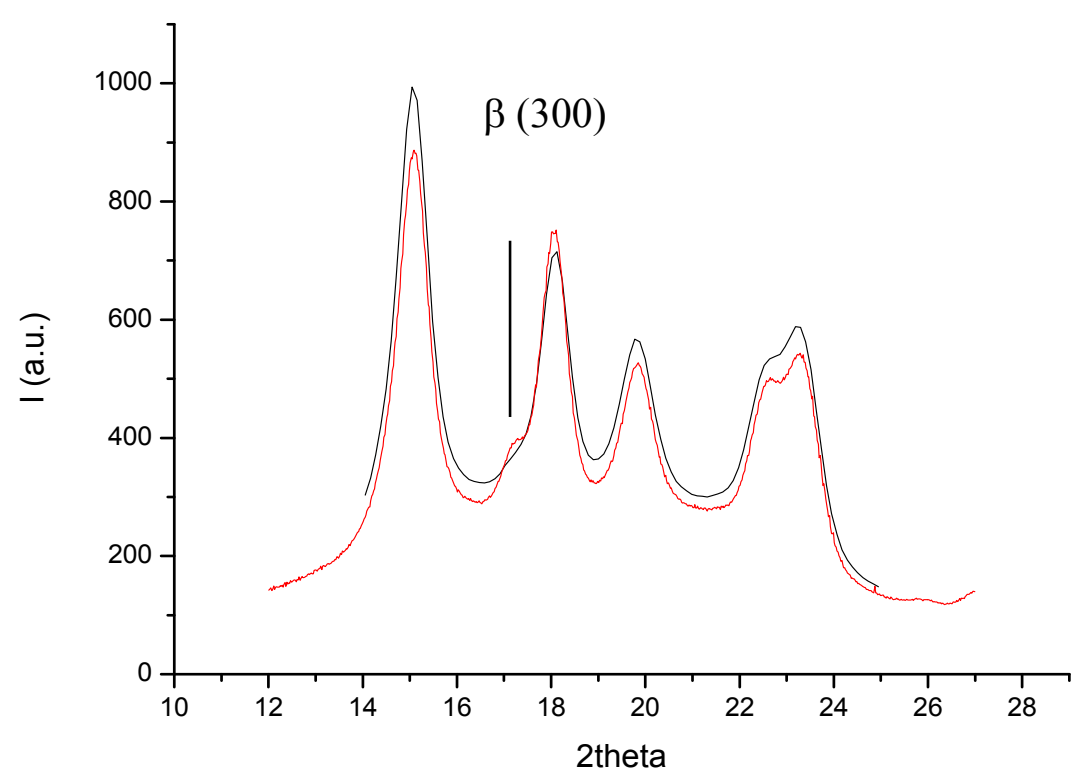

Figure 11 : XRD patterns of PP+15wt\%PP-g-M +10wt $\%($ DER671+NBDA) (red) and PP+ $15 \mathrm{wt} \% \mathrm{PP}-\mathrm{g}-\mathrm{MA}+10 \mathrm{wt} \%$ (DER671+NBDA) annealed at $135^{\circ} \mathrm{C}$ for $12 \mathrm{~h}$ (black). 
Table 7 : Mechanical properties and crystalline conformations for different samples (annealed or not)

\begin{tabular}{|l|c|c|}
\hline Samples & Phase & Re $\left(\mathrm{kJ} . \mathrm{m}^{-2}\right)$ \\
\hline PPH3060 & $\alpha$ & $6.5 \pm 0.6$ \\
\hline PP+20wt\%PP-g-MA & $\alpha$ & $4.2 \pm 0.8$ \\
\hline PP+20wt\%PP-g-MA+26wt\%(DER671+DEH84) & $\alpha+\beta$ & $7.5 \pm 0.4$ \\
\hline PP+15wt\%PP-g-MA+10wt\%(DER671+NBDA) & $\alpha+\beta$ & $9.4 \pm 0.7$ \\
\hline $\begin{array}{l}\text { PP+20wt PP-g-MA+26wt\%(DER671+DEH84 } \\
24 h \text { at } 135{ }^{\circ} \mathrm{C}\end{array}$ & $\alpha$ & $3.2 \pm 0.3$ \\
\hline $\begin{array}{l}\text { PP+15wt\%PP-g-MA+10wt\%(DER671+NBDA) } \\
24 h \text { at } 135^{\circ} \mathrm{C}\end{array}$ & $\alpha$ & $3.8 \pm 0.4$ \\
\hline
\end{tabular}

As we can see, the resistance to an impact decreases importantly for the annealed samples, going from 7.5 to $3.2 \mathrm{~kJ} . \mathrm{m}^{-2}$ for the sample with DEH84. We can therefore conclude that the appearance of the $\beta$-phase is responsible for the improvement of the resilience.

The same observations were noticed by $\mathrm{Chen}^{41}$ and al. with a homopolymer PP. The PP presenting only $\alpha$-phase presents fracture energy of $6.2 \mathrm{~kJ} . \mathrm{m}^{-2}$ and the one with $100 \% \beta$-phase $9.3 \mathrm{~kJ} . \mathrm{m}^{-2}$. The $\beta$-phase is therefore at the origin of the important increase of the resilience in PP reinforced by TS nodules.

\section{CONCLUSION}

First, the synthesis of the TS in the molten PP matrix was studied, showing the creation of a covalent bond between the TS and the PP via the use of PP-g-MA. We also observed the morphology presented by the TS as nodules of $0.5 \mu \mathrm{m}$ diameter but equally the presence of "domains" which should be composed of TS/ PP-g-MA and are an interface component PP-gTS. The synthesis of TS in a polyolefin matrix has an impact not only on the morphology and 
mechanical properties but also on the crystalline structure. Actually, this work evidenced that there is an intimate relation between morphology, compatibilization, mechanical properties and evolution of crystalline structure.

The mechanical properties analyzed strengthened once more the role of PP-g-MA. The in situ formation of PP-g-TS created at the PP/TS interface via PP-g-MA improves the elongation at break and the resilience. Young's modulus is improved by the presence of TS. In fact, the PP-g-MA not only ensure a better compatibility between TS and PP but will also refine the nodules distribution creating a more homogenous material. There is therefore an important relation between morphology, mechanical properties and bond between the two phases.

Nevertheless, the important increase for some samples of the resistance to an external impact was not expected since the presence of TS creates a default that leads to the propagation of cracks but the appearance of interface component PP-g-TS tends to reduce this aspect. Another phenomenon is therefore at the origin of this reinforcement. An investigation of the crystalline structure was carried out and the presence of a new crystalline form was detected on the presence of high amount of TS, the $\beta$-phase. The influence of PP-g-MA was once more proved since its presence induced the increase of $\beta$-phase. The epoxy based thermosetting created in situ is not only able to reinforce the tensile properties but will also be a $\beta$-nucleating agent, promoter of the crystallization under $\beta$-form and not under $\alpha$-form. 


\section{AUTHOR INFORMATION}

\section{Corresponding Author}

Véronique Bounor-Legaré - Université de Lyon, Université Lyon1, Ingénierie des Matériaux Polymères, CNRS UMR 5223, 15 Boulevard André Latarjet, 69622, Villeurbanne, France

Email : bounor@univ-lyon1.fr

\section{Present Addresses}

Luisa Barroso Gago - Université de Lyon, Université Lyon1, Ingénierie des Matériaux Polymères, CNRS UMR 5223, 15 Boulevard André Latarjet, 69622, Villeurbanne, France Mathilde Auclerc - Université de Lyon, Université Lyon1, Ingénierie des Matériaux Polymères, CNRS UMR 5223, 15 Boulevard André Latarjet, 69622, Villeurbanne, France

Karim Delage - Université de Lyon, Université Lyon1, Ingénierie des Matériaux Polymères, CNRS UMR 5223, 15 Boulevard André Latarjet, 69622, Villeurbanne, France

Nicolas Garois - Hutchinson, Centre de Recherche, Rue Gustave Nourry - B.P. 31, 45120, Chalette-sur-Loing, France

Philippe Cassagnau - Université de Lyon, Université Lyon1, Ingénierie des Matériaux Polymères, CNRS UMR 5223, 15 Boulevard André Latarjet, 69622, Villeurbanne, France Véronique Bounor-Legaré - Université de Lyon, Université Lyon1, Ingénierie des Matériaux Polymères, CNRS UMR 5223, 15 Boulevard André Latarjet, 69622, Villeurbanne, France 


\begin{abstract}
Author Contributions
The manuscript was written through contributions of all authors. All authors have given approval to the final version of the manuscript. $\$$ These authors contributed equally. (match statement to author names with a symbol)
\end{abstract}

\title{
ACKNOWLEDGMENT
}

The authors are grateful to the joint laboratory IMP/ HUTCHINSON for the financial support. The authors would like to thank Pierre Alcouffe and all the staff of the Technological Center of Microstructures of the University of Lyon 1 for their kind assistance in electron. microscopy characterizations. The authors would like also to thank Pr René Fulchiron for his expertise and discussion on the PP crystalline phase evolution.

$\begin{array}{ll}\text { ABBREVIATIONS } \\ \Delta \mathrm{H}_{\mathrm{m}} & \text { Melting enthalpy } \\ \Delta \mathrm{H}^{\circ}{ }_{\mathrm{m}} & \text { Melting enthalpy of a theoretical 100\% crystalline PP } \\ \sigma_{\text {break }} & \text { Tensile at break } \\ \text { DEH } 84 & \text { Epoxyde resin DEH } 84 \\ \text { DER 671 } & \text { Epoxyde resin DER 671 } \\ \text { DGEBA } & \text { Bisphenol A diglycidyl ether } \\ \text { DSC } & \text { Differential Scanning Calorimetry } \\ \text { FTIR } & \text { Fourier-Transform Infrared Spectroscopy } \\ \text { MFI } & \text { Melt flow Index } \\ \text { M } & \text { Number Average Molecular Weight } \\ \text { M } & \text { Weight Average Molecular Weight } \\ \text { NBDA } & \text { Diamine norbornane } \\ \text { PP-g-MA } & \text { Polypropylene grafted maleic anhydride } \\ \text { Re } & \text { Resilience } \\ \text { T } & \text { Temperature } \\ \text { TS } & \text { Epoxy based thermosetting } \\ \text { TEM } & \text { Transmission Electron Microscopy } \\ \end{array}$


$\mathrm{T}_{\mathrm{m}} \quad$ Melting temperature

$\mathrm{T}_{\mathrm{g}} \quad$ Glass transition temperature

TP Thermoplastic

WAXS X-rays scattering at wide angles 


\section{REFERENCES}

(1) Plastics Europe Annual Review 2017-2018.

(2) Bartczak, Z.; Galeski, A. Mechanical Properties of Polymer Blends, Polymer Blends Handbook, 2014, 1203-1297.

(3) Pukánszky, B.; Tüdõs, F. Miscibility and mechanical properties of polymer blends, Macromolecular Symposia - Polyolefin Characterization, 1990, Vol.38, 221-231.

(4) Xie, Z.; Sheng, J.; Wan, Z. Mechanical Properties and Morphology of Polypropylene/Polystyrene Blends, Journal of Macromolecular Science - Part B, 2001, Vol. 40, $251-261$

(5) Ujhelyiová, A.; Horbanová, L.; Petková, M.; Ryba, J.; Annus, J. Polypropylene Crystallisation in the Presence of Inorganic Additives, Fibres \& Textiles in Eastern Europe, 2019, Vol.27, 30-38.

(6) Mittal, P.; Naresh, S.; Luthra, P.; Singh, A.; Singh Dhaliwal, J.; Singh Kapur, G. Polypropylene composites reinforced with hybrid inorganic fillers : Morphological, mechanical, and rheological properties, Journal of Thermoplastic Composite Materials, 2018, Vol. 32, 848864.

(7) Gachter, R.; Muller, H. Plastics Additives Handbook, 2nd Edition, 1990.

(8) Xing, Z.L.; Jiang, H. Soundproofing effect of polypropylene/inorganic particle composites, Composites Part B: Engineering, 2012, Vol. 43, 1995-1998.

(9) Tolinski, M. Additives for Polyolefins - Chapter 7 - Overview of Fillers and Fibers, 2009. 
(10) Fenouillot, F.; Perier-Camby, H. Formation of a Fibrillar Morphology of a Crosslinked Epoxy in a Polystyrene Continuous Phase by Reactive Extrusion, Polymer Engineering and Science, 2004, Vol.44, 625-637.

(11) Bahloul, W.; Bounor-Legaré, V.; Fenouillot, F.; Cassagnau, P. EVA/PBT nanostructured blends synthesized by in situ polymerization of cyclic cBT (cyclic butylene terephthalate) in molten EVA, Polymer, 2009, Vol. 50, 2527-2534.

(12) Cassagnau, P.; Nietsch, T.; Bert, M.; Michel, A. Reactive blending by in situ polymerization of the dispersed phase, 1998, Polymer, Vol. 40, 131-138.

(13) Macosko, C. W.; Guégan, P.; Khandpur, A. K. Compatibilizers for Melt Blending: Premade Block Copolymers, Macromolecules, Vol.29, 5590-5598, 1996.

(14) Leibler, L. Block copolymers at interfaces, Physica A: Statistical Mechanics and its Applications, 1992, Vol.172, 258-268.

(15) Meynié, L. Evolution et contrôle de la morphologie d'un mélange thermoplastique/thermodurcissable polymérisé sous cisaillement(thesis), INSA Lyon, 2003.

(16) Mengual, A.; Juárez, D.; Balart, R.; Ferrándiz, S. PE-g-MA, PP-g-MA and SEBS-g-MA compatibilizers used in material blends, Procedia Manufacturing, 2017, Vol. 13, 321-326.

(17) Akbari, M.; Zadhoush, A.; Haghighat, M. PET/PP blending by using PP-g -MA synthesized by solid phase, Applied Polymer Science, 2007, Vol. 104, 3986 - 3993. 
(18) Simões, R.; Viana, J.C.; Dias, G. R.; Cunha, A. M. Mechanical Behavior of the Lamellar Structure in Semi-Crystalline Polymers, Materials Science Forum, 2013, Vol. 730-732, 10061011.

(19) Menyhárd, A.; Suba, P.; László, Z.; Fekete, H. M.; Mester, Á. O.; Horváth, Z.; Vörös, G.; Varga, J.; Móczó, J. Direct correlation between modulus and the crystalline structure in isotactic polypropylene, Express Polymer Letters, 2015, Vol. 9, 308-320.

(20) Papageorgiou, D. G.; Chrissafis, K.; Bikiaris, D. N. $\beta$-Nucleated Polypropylene : Processing, Properties and Nanocomposites, Polymer Reviews, 2015, Vol. 55, 596-629.

(21) Cascone, A.; Fulchiron, R. Squeeze flow induced crystallization monitoring in polymers, Polymer Testing, 2011, Vol. 30, 760-764.

(22) Jingjiang, L.; Xiufen, W.; Qipeng, G. The $\beta$ Crystalline Form of Wollastonite- Filled Polypropylene, Journal of Applied Polymers, 1990, Vol.41, 2829-2835.

(23) Li, X.; Hu, K.; Ji, M.; Huang, Y.; Zhou, G. Calcium Dicarboxylates Nucleation of $\beta$ Polypropylene, Journal of Applied Polymers, 2002, Vol. 86, 633-638.

(24) Zhang, P.; Liu, X.; Li, Y. Influence of b-nucleating agent on the mechanics and crystallization characteristics of polypropylene, Materials Science and Engineering A, 2006, Vol.343, 310-313.

(25) Wong, B.; Baker, W. E. Melt rheology of graft modified Polypropylene, Polymer, 1997, Vol.38, 2781-2789. 
(26) Wang, X.; Tzoganakis, C.; Rempel, G. Chemical Modification of Polypropylene with Peroxide/ Pentaerythritol Triacrylate by Reactive Extrusion, Journal of Applied Polymer Science, 1996, Vol. 61, 1395-1404.

(27) Wunderlich, B. Macromolecular Physics : Crystals, Structure, Morphology and Defects, Elsevier Science \& Technology, 1973.

(28) Matsumoto, K.; Nagai, M.; Hamakawa, K.; Nishitsuji, S.; Inoue, T. Design of a SuperDuctile Polypropylene/Polycarbonate Blend with High Heat Resistance by using Reactive Plasticizer, Journal of Applied Polymers, 2012, Vol.129, 443-448.

(29) Kim, G. M.; Michler, G. H.; Rösch, J.; Mülhaupt, R. Micromechanical deformation processes in toughened $\mathrm{PP} / \mathrm{PA} / \mathrm{SEBS}-\mathrm{g}-\mathrm{MAblends}$ prepared by reactive processing, Acta Polymer, 1998, Vol 49, 88-95.

(30) Mazidi, M. M.; Aghjeh, M. K. R.; Hasanpour, M. Fracture resistance and micromechanical deformations in PP/PA6/EPDM ternary blends: Effect of rubber functionality, dispersion state and loading conditions, Engineering Fracture Mechanics, 2018, Vol. 191, 65-81.

(31) Hu, G.; Cartier, H.; Plummer, C. Reactive Extrusion: Toward Nanoblends, Macromolecules, 1999, Vol.32, 4713-4718.

(32) Vandenburg, H. J.; Clifford, A. A.; Bartle, K. D.; Carroll, J.; Newton, I.; Garden, L. M.; Dean, J. R.; Costley, C. T. Analytical Extraction of Additives From Polymers, Analyst, 1997, Vol. 122, R101-R115. 
(33) Bream, C.E.; Hornsby, P.R. Structure Development in Thermoset Recycled-Filled Polypropylene Composites, Polymer Composites, 2000, Vol.21, 417-435.

(34) Oyama, H. T.; Nakayama, R.; Takase, K.; Furuta, M. Drastic improvement in thermal stability of polymer alloys by formation of daughter micelles at the reactive interface, Polymers, 2018, Vol. 137, 107-111.

(35) Meille, S. V.; Ferro, D. R.; Bruckner, S.; Lovinger, A. J.; Padden, F. J. Structure of $\beta$ Isotactic Polypropylene : A Long-Standing Structural Puzzle, Macromolecules, 1994, Vol.27, 2615-2622.

(36) Liu, J.; Zhu, X.; Cao, Z. Poly(Acrylonitrile-Butadiene-Styrene) as a Special $\beta$-Nucleating Agent on the Toughness of Isotactic Polypropylene, Polymers, 2019, Vol.11, Article 1894.

(37) Lin, Z.; Guan, Z.; Xu, B.; Chen, C.; Guo, G.; Zhou, J.; Xian, J.; Cao, L.; Wang, Y.; Li, M.; Li, W. Crystallization and melting behavior of polypropylene in b-PP/polyamide 6 blends containing PP-g-MA, Journal of Industrial and Engineering Chemistry, 2013, Vol. 19, 692-697.

(38) Fine, T.; Pascault, J. P. Structured Thermoplastic/Thermoset Blends Using Block Copolymers, Macromolecular Symposia, 2006, Vol.245, 375-385.

(39) L. Xu, K. Xu, X. Zhang, F. Liu, M. Chen, "The mechanism for fracture resistance in $\beta$ nucleated isotactic polypropylene", Polymers Advanced Technologies, Vol.21, 807-816, 2010.

(40) Shang, Y.; Zhao, J.; Li, J.; Wu, Z.; Jiang, S. Investigations in annealing effects on structure and properties of $\beta$-isotactic polypropylene with X-ray synchrotron experiments, Colloid Polymer Science, 2014, Vol.292, 3205-3221. 
(41) Chen, H.B.; Karger-Kocsisb, J.; Wu, J.S.; Varga, J. Fracture toughness of a- and b-phase polypropylene homopolymers and random- and block-copolymers, Polymer, 2002, Vol.43, 65056514.

Supporting informations consisting in five figures (S1to S5 respectively) are dealing with TEM Images of PP+15wt\%PP-g-MA+10wt\%(DER671+NBDA) (Figure S1), DSC of the soluble part of the sample PP+20wt\%PP-g-MA+ 26wt\% (DER671+DEH84) after Soxhlet extraction in xylene (Figure S2), FTIR spectra of PP+20wt\%PP-MA+26wt\%(DER671+DEH84) before (black) and after (red) Soxhlet extraction in xylene (Figure S3), DSC of PP $+15 w t \% P P-g-$ $\mathrm{MA}+10 \mathrm{wt} \%(\mathrm{DER} 671+\mathrm{NBDA})$ with NBDA injected at L/D = 17D (black), L/D = 32D (red) and $\mathrm{L} / \mathrm{D}=42 \mathrm{D}$ (blue) (Figure S4) and XRD patterns of $\mathrm{PP}+26 \mathrm{wt} \%(\mathrm{DER} 671+\mathrm{NBDA})$ (black) and PP+20wt\%PP-g-MA+26wt\%(DER671+NBDA) (red) (Figure S5). 